\title{
The Introduction of Clinical Audit as a Quality Improvement Tool in Gaza
}

\author{
Said Alyacoubi $\mathbb{D}^{\prime}$ \\ Loai Albaraqouni ${ }^{2}$ \\ Khamis Elessi (D) \\ Bettina Bottcher (D) \\ 'Evidence-Based Medicine Unit, Faculty \\ of Medicine, Islamic University of Gaza, \\ Gaza, Gaza Strip, Palestine; ${ }^{2}$ Centre for \\ Research in Evidence-Based Practice, \\ Bond University, Robina, Queensland, \\ Australia
}

Background: Clinical audit plays a fundamental role in improving the quality of patient care and hence, is considered a cornerstone of clinical governance. This study evaluates clinical audit as a newly introduced quality improvement tool in the healthcare system of the Gaza Strip.

Methods: Medical students and healthcare professionals who conducted audits between 2015 and 2018 were invited to fill in an online survey from October 12 to November 2, 2018. Data were collected on different aspects of the audit process.

Results: A total of 62 audits were collected. Training in clinical governance was received by 55 authors (88.7\%) while senior supervision was available in 56 audits (90.3\%). Audits were performed across different hospitals and specialties with 18 audits (29\%) in obstetrics, 16 audits $(25.8 \%)$ in medicine and 11 audits $(17.7 \%)$ in each of surgery and paediatrics. A clear trend of increasing numbers of audits was observed with 4 audits $(6.4 \%)$ conducted in 2015 , 12 audits (19.3\%) in 2016, 22 audits (35.4\%) in 2017, and 24 audits (38.7\%) in 2018. Only 32 audits $(51.6 \%)$ were presented to the local staff. The audit cycle was completed in 13 projects $(20.9 \%)$ with only seven of them reporting subsequent improvements in practice.

Conclusion: The rise in the number of audits reflects a growing awareness of its key role in healthcare and patient safety. However, the closure of loops and the actual implementation of recommendations are still lagging behind. Therefore, more focused efforts are needed to implement changes and ensure continuous evaluation of their effectiveness.

Keywords: quality improvement, clinical audit, evidence-based medicine, Gaza, Palestine

\section{Introduction}

Clinical audits play a fundamental role in improving the quality of clinical practice and patient safety. ${ }^{1-3}$ The audit cycle involves observing practice, setting standards, comparing practice with standards, implementing changes, and finally observing new practice. ${ }^{4-6}$ Closing the audit cycle is essential to achieve sustainable improvements in healthcare. ${ }^{2,7,8}$ In practice, the cycle is often incomplete, and the problems are left unresolved, which can potentially result in clinical auditing being a timeand resource-wasting activity. ${ }^{9-12}$

Clinical audit was implemented relatively recently as a quality improvement (QI) tool in the healthcare system of the Gaza Strip. For example, teaching concepts of QI work and clinical audit were only introduced into the curriculum of one of the two local medical schools in 2015. This led to the completion of a number of audit projects by medical students for the first time in 2015. ${ }^{13-15}$ A notable rise of QI work conducted by medical students was observed in the following years. In 2017, the Palestinian Medical Council (PMC) introduced a general requirement for healthcare
Correspondence: Said Alyacoubi Southampton General Hospital, Southampton, SOI6 6YD, UK Email said-alyacoubi@hotmail.com 
professionals, including interns and residents, to partake in QI activities. These measures sparked wider engagement in audit activities as well as a broad awareness of the importance of QI work amongst medical students and healthcare professionals. However, evidence of monitoring of audit activities and subsequent improvements in clinical practice is still lacking. Consequently, concerns were raised regarding the effectiveness of clinical audits in improving the quality of patient care in Gaza Hospitals.

Therefore, this study was designed to track and evaluate the clinical audits that were conducted in the Gaza Strip between 2015 and 2018. Furthermore, it explored factors that could contribute towards producing more impactful audits in order to improve the quality of patient care in Gaza hospitals.

\section{Methods}

\section{Design and Setting}

An online survey was used to collect information on the audit projects conducted in the Gaza Strip-Palestine between 2015 and 2018 (Appendix 1). The survey was disseminated through email communications and on local and institutional social media platforms, including those of the Palestinian Ministry of Health $(\mathrm{MoH})$ and local universities. The survey was accessible from October 12 to November 2, 2018.

\section{Participants}

Students, doctors and other healthcare professionals were invited to complete the survey if they had an audit project conducted during the specified period (2015-2018).

\section{Main Outcome Measures}

Data were collected on different aspects of the audit process, including audit teams, approval, availability of training and supervision, location of study, specialty, target population, audit standards, data collection and analysis, outcomes, presentation, publication, completion of cycle and subsequent changes in practice.

\section{Data Analysis}

Data analysis was mainly performed using SPSS statistical software. Certain parts of the data analysis were performed using Microsoft Excel Sheets.

\section{Ethical Statement}

The approval of this study was obtained from the General Directorate of Human Resources Development at the Ministry of Health $(\mathrm{MoH})$ in accordance with the Declaration of Helsinki. The General Directorate is the body responsible for regulating clinical research and quality improvement studies at Palestinian hospitals. All participants provided informed consent to take part in this study.

\section{Results}

A total of 62 audits were registered via the survey. Students were involved in 46 audits $(74.1 \%)$ while practicing clinicians were involved in 29 audits (46.7\%). Only one of the audits was conducted by a nurse (1.6\%). Fifty audit groups (80.6\%) sought an approval from the General Directorate of Human Resources Development at the $\mathrm{MoH}$ and/or the local healthcare facility administration before commencing their work. Training in clinical auditing was received by 55 authors $(88.7 \%)$. Senior supervision was available in 56 audits (90.3\%), with one supervisor having been mentioned in 42 of them $(67.7 \%)$.

The majority of audits $(17 ; 27.4 \%)$ were multicentric and conducted at more than one healthcare facility. Thirteen audits (20.9\%) were conducted solely at AlHelal Al-Emirati Hospital, 11 audits (17.7\%) at Al-Naser Hospital, 7 audits (11.3\%) at Al-Shifa Hospital, 5 audits (8\%) at the European Gaza Hospital, one audit (1.6\%) at each of Al-Aqsa, Indonesian, Al-Rantisi and Gaza Mental Health Hospitals, and 5 audits (8\%) at different community health clinics (Table 1). Audits were also performed in various specialties, including 18 audits (29\%) in obstetrics, 16 audits $(25.8 \%)$ in medicine, 11 audits $(17.7 \%)$ in each of surgery and paediatrics, and six audits $(9.6 \%)$ in other specialties (three audits in emergency medicine and one audit in each of intensive care medicine, psychiatry and radiology) (Table 2). Patients were the target population in the majority of these audits $(59 ; 95.1 \%)$ while only three audits $(4.8 \%)$ targeted working staff.

A clear trend of increasing numbers of audits was observed with 4 audits (6.4\%) conducted in 2015, 12 audits $(19.3 \%)$ in 2016, 22 audits (35.4\%) in 2017 and 24 audits (38.7\%) in 2018. Clear comparative standards were identified in 54 audits (87\%) while eight audits (13\%) reported not setting standards at all. Among those with chosen standards, 40 audits (64.5\%) used international guidelines while only 14 audits (22.5\%) referred to local practice guidelines (Table 2). Most audits $(33 ; 53.2 \%)$ collected data retrospectively whereas 15 audits $(24.2 \%)$ collected data prospectively and 14 audits $(22.5 \%)$ used both methods. Audit teams used different methods of data collection tools including 
Table I Location of Studies

\begin{tabular}{|l|c|}
\hline Multi-centric audits & $17(27.4 \%)$ \\
\hline Al-Helal Al-Emirati Hospital & $13(20.9 \%)$ \\
\hline Naser Hospital & $I I(17.7 \%)$ \\
\hline Al-Shifa Hospital & $7(1 \mathrm{I} .3 \%)$ \\
\hline European Gaza Hospital & $5(8 \%)$ \\
\hline Community Health clinics & $5(8 \%)$ \\
\hline Al-Aqsa Hospital & $\mathrm{I}(\mathrm{I} .6 \%)$ \\
\hline Al-Indonesia Hospital & $\mathrm{I}(\mathrm{I} .6 \%)$ \\
\hline Gaza Mental Health Hospital & $\mathrm{I}(\mathrm{I} .6 \%)$ \\
\hline Al-Dorra Hospital & $\mathrm{I}(\mathrm{I} .6 \%)$ \\
\hline
\end{tabular}

online surveys, written questionnaires, hospital records, phone or face-to-face interviews, observation of practice, or a combination of more than one method. Data analysis was also performed using different methods including SPSS software, Microsoft Excel Sheets, manual analysis or a combination of more than one method.

Improvement in documentation was recommended in 44 audits $(71 \%)$, development of national guidelines in 37 audits $(59.6 \%)$, staff training in 32 audits (51.6\%) and patient education in 14 audits $(22.5 \%)$. Thirty-two audits

Table 2 Characteristics of Audits

\begin{tabular}{|l|c|}
\hline Audit Characteristics & $\begin{array}{c}\text { Number and Percentage (\%) } \\
\mathbf{n = 6 2}\end{array}$ \\
\hline Number of audits per year \\
\hline 2015 & $4(6.4 \%)$ \\
2016 & $12(19.3 \%)$ \\
2017 & $22(35.4 \%)$ \\
2018 & $24(38.7 \%)$ \\
\hline Specialties & \\
\hline Obstetrics and & $18(29.0 \%)$ \\
Gynaecology & $16(25.8 \%)$ \\
Medicine & $11(17.7 \%)$ \\
Surgery & $11(17.7 \%)$ \\
Paediatrics & $6(9.7 \%)$ \\
Other & \\
\hline Standards & $14(22.5 \%)$ \\
\hline Local practice guidelines & $40(64.5 \%)$ \\
International standards & $6(9.7 \%)$ \\
No standards identified &
\end{tabular}

Table 3 Reported Outcomes of Audits

\begin{tabular}{|l|c|}
\hline Audit Outcomes & $\begin{array}{l}\text { Number and } \\
\text { Percentage (\%) } \\
\mathbf{n = 6 2}\end{array}$ \\
\hline Recommendations made $^{\dagger}$ & $44(71.9 \%)$ \\
\hline Improvement of documentation & $37(59.6 \%)$ \\
Development of national guidelines & $32(51.6 \%)$ \\
Staff training & $14(22.5 \%)$ \\
Patient education & $32(51.6 \%)$ \\
\hline Environment for sharing results and recommendations & \\
\hline Facility-based audit meeting with the team & $48(77.4 \%)$ \\
Local meeting & $23(37.0 \%)$ \\
Regional, national or international meeting & $13(20.9 \%)$ \\
Published as abstract or paper in peer-reviewed & $5(8.1 \%)$ \\
journals & $7(11.3 \%)$ \\
\hline Results never shared & \\
\hline Audit cycle and improvements & \\
\hline Audit cycle completed & \\
Improvements made in practice &
\end{tabular}

Notes: ${ }^{\dagger}$ Total $>100 \%$, as more than one recommendation might have been made per project. ${ }^{\ddagger}$ Total $>100 \%$, as results might have been presented more than once.

$(51.6 \%)$ were presented to the local staff at the healthcare facility where the work was originally conducted while 48 audits $(77.4 \%)$ were presented at other local meetings and 23 audits $(37.0 \%)$ were presented at national or international meetings. The results of five audits (8.0\%) were not presented anywhere and none of them had completed the cycle (Table 3 ).

The abstracts of 13 audits (20.9\%) were published in supplements of peer-reviewed journals. Furthermore, the audit cycle was completed in 13 projects $(20.9 \%)$, with only seven of them (11.3\%) reporting subsequent changes in clinical practice (Table 3). The common factors shared amongst those completed projects were found to be training, availability of supervision and setting clear comparative standards.

\section{Discussion}

The lack of local and central registration systems makes it difficult to broadly track and evaluate the progress and development of QI work across the Gaza Strip. However, uuntil 2015, no evidence was available of any systematic QI work undertaken by medical students or healthcarepractitioners in Gaza Hospitals.

The implementation of measures endorsing audit activities by local medical schools and PMC led to a growing awareness of the importance of QI work and harnessed the 
cooperation between healthcare professionals and medical students to conduct clinical audits. This was reflected by a steady increase in the number of audits undertaken in local healthcare practice. An increasing number of abstract submissions to the international Lancet Palestinian Health Alliance (LPHA) annual conference were also observed between 2015 and 2018 with some positive impact reports. $^{16,17}$

Crucially, the cycle has to be completed in order to assess the impact of the original audit. In this study, the cycle was found to be completed in only one fifth of all projects $(20.9 \%)$. This number is low but, nonetheless, similar to those reported in other studies. ${ }^{2,9,10,18,19}$ Although such studies were undertaken in the context of well-developed and supported audit programmes unlike that of this study, efforts should still be made towards achieving higher completion rates in our local practice and elsewhere. Factors that were shared between successfully completed audit cycles were found to be most importantly training of audit teams, availability of supervision and having clear comparative standards in place before commencing the work.

Although the observed spike in audit numbers is encouraging, the impact of audit activities in Gaza is still lagging behind with only seven studies (11.3\%) reporting subsequent improvements in practice. Efforts made by regulatory organisations and medical schools might have supported the increase in the number of audits conducted by trainee doctors and medical students but did not necessarily lead to production of impactful projects. In general, audits conducted with local staff being involved and under senior leadership proved to be the most effective in initiating and leading improvements. ${ }^{7-9}$ The provision of feedback to the local staff through presentation of results at internal meetings has also been shown to be effective. ${ }^{12}$ Other measures such as the availability of dedicated support teams or the provision of protected time for QI work $^{5,20-23}$ are often difficult to implement in the case of low-income countries. ${ }^{24,25}$ Therefore, it is imperative to focus on factors that can potentially be supported in such settings in order to produce QI work with the highest possible impact. $^{25,26}$

Limitations of this work include selection bias as the study mainly relied on disseminating the online form through social media platforms known to the local healthcare community. The team also used email communications in order to reach out to others potentially involved in audit activities. Nevertheless, a number of audits conducted during the study period are still believed to be missing. In addition, audit impacts were not evaluated individually, and the study relied on the teams' evaluation of their own work and its impact.

\section{Conclusions}

While only a few audits were conducted prior to 2015, the constant rise in numbers proves a growing awareness of the importance QI efforts. However, the actual implementation of the changes is still lagging behind. Hence, focused efforts supported by both clinical and administrative leaderships are needed to implement recommendations and action plans.

\section{Abbreviations}

QI, quality improvement; MoH, Ministry of Health; PMC, Palestinian Medical Council; LPHA, Lancet Palestinian Health Alliance.

\section{Funding}

This study received no funding.

\section{Disclosure}

The abstract of this paper was presented by Dr Said Alyacoubi at the Lancet Palestinian Alliance Health Conference in March 2019 as a poster presentation. The authors report no conflicts of interest in this work.

\section{References}

1. National Institute for Clinical Excellence (NICE). Principles for best practice in clinical audit. Int J Health Care Qual Assur. 2002;15(7): ijhcqa.2002.06215gae.004. doi:10.1108/ijhcqa.2002.06215gae.004

2. Gnanalingham J, Gnanalingham MG, Gnanalingham KK. An audit of audits: are we completing the cycle? J R Soc Med. 2001;94 (6):288-289. doi:10.1177/014107680109400609

3. Øvretveit J. Understanding the conditions for improvement: research to discover which context influences affect improvement success. $B M J$ Qual Saf. 2011. doi:10.1136/bmjqs.2010.045955

4. Pawson R, Greenhalgh T, Harvey G, Walshe K. Realist review - a new method of systematic review designed for complex policy interventions. J Health Serv Res Policy. 2005;10(1_suppl):21-34. doi:10.1258/1355819054308530

5. Kaplan HC, Froehle CM, Cassedy A, Provost LP, Margolis PA. An exploratory analysis of the model for understanding success in quality. Health Care Manage Rev. 2013;38(4):325-338. doi:10.1097/ HMR.0b013e3182689772

6. Spurgeon P, Mazelan PM, Barwell F. Medical engagement: a crucial underpinning to organizational performance. Health Serv Manag Res. 2011;24(3):114-120. doi:10.1258/hsmr.2011.011006

7. McDonald KM, Schultz EM, Chang C. Evaluating the state of quality-improvement science through evidence synthesis: insights from the closing the quality gap series. Perm J. 2013;17(4):52-61. doi:10.7812/TPP/13-010

8. Ivers NM, Sales A, Colquhoun H, et al. No more "business as usual" with audit and feedback interventions: towards an agenda for a reinvigorated intervention. Implement Sci. 2014;9(1). doi:10.1186/ 1748-5908-9-14 
9. Taylor L, Jones S. Clinical governance in practice: closing the loop with integrated audit systems. J Psychiatr Ment Health Nurs. 2006;13 (2):228-233. doi:10.1111/j.1365-2850.2006.00945.x

10. Iqbal H, Pidikiti P. Audit of orthopaedic audits in an English teaching hospital: are we closing the loop? Open Orthop J. 2010;4 (1):188-192. doi:10.2174/1874325001004010188

11. Wagner DJ, Durbin J, Barnsley J, Ivers NM. Beyond quality improvement: exploring why primary care teams engage in a voluntary audit and feedback program. BMC Health Serv Res. 2017;17(1). doi:10.1186/s12913-017-2765-3

12. Ivers N, Jamtvedt G, Flottorp S, et al. Audit and feedback: effects on professional practice and healthcare outcomes. Cochrane Database Syst Rev. 2012. doi:10.1002/14651858.CD000259.pub3

13. Alyacoubi S, Abuowda Y, Albarqouni L, Böttcher B, Elessi K. Inpatient management of community-acquired pneumonia at the European Gaza Hospital: a clinical audit. Lancet. 2018;391 Suppl 2:391. doi:10.1016/S0140-6736(18)30406-9

14. Abukhalil M, Bottcher B, Mehjez O, Alankah L, Abuyusuf M, Hasan S. Medical records of emergency caesarean sections in the Gaza Strip: a clinical audit. Lancet. 2018;391:S26. doi:10.1016/ s0140-6736(18)30351-9

15. Musallam R, Salem N, Al Halol R, Al Deeb H, Bottcher B, AlHamaida H. Management of pregnancy loss in the first trimester: a retrospective audit. Lancet. 2018;391:S34. doi:10.1016/S01406736(18)30400-8

16. Alrumi N, Aghaalkurdi M, Habib H, Abed S, Böttcher B. Infection control measures in neonatal units: implementation of change in the Gaza-Strip. J Matern Neonatal Med. 2019. doi:10.1080/ 14767058.2019.1576168

17. Zimmo KM, Laine K, Fosse E, et al. Impact of animated instruction on tablets and hands-on training in applying bimanual perineal support on episiotomy rates: an Intervention Study. Int Urogynecol J. 2018;30(8):1343-1350. doi:10.1007/s00192-018-3711-6
18. John CM. An audit of paediatric audits. Arch Dis Child. 2004;89 (12):1128-1129. doi:10.1136/adc.2003.032565

19. Guryel E, Acton K, Patel S. Auditing orthopaedic audit. Ann R Coll Surg Engl. 2008;90(8):675-678. doi:10.1308/003588408X318147

20. Johnston G, Crombie IK, Davies HTO, Alder EM, Millard A. Reviewing audit: barriers and facilitating factors for effective clinical audit. Qual Health Care. 2000;9(1):23-36. doi:10.1136/qhc.9.1.23

21. Anderson P, Fee P, Shulman R, Bellingan GJ, Howell DCJ. Audit of audit: review of a clinical audit programme in a teaching hospital intensive care unit. $B r \quad J$ Hosp Med. 2012;73(9):526-529. doi:10.12968/hmed.2012.73.9.526

22. Coles E, Wells M, Maxwell M, et al. The influence of contextual factors on healthcare quality improvement initiatives: what works, for whom and in what setting? Protocol for a realist review. Syst Rev. 2017;6(1). doi:10.1186/s13643-017-0566-8

23. Kaplan HC, Brady PW, Dritz MC, et al. The influence of context on quality improvement success in health care: a systematic review of the literature. Milbank $Q$. 2010;88(4):500-559. doi:10.1111/j.14680009.2010.00611.x

24. Hut-Mossel L, Welker G, Ahaus K, Gans R. Understanding how and why audits work: protocol for a realist review of audit programmes to improve hospital care. BMJ Open. 2017;7(6):e015121. doi:10.1136/ bmjopen-2016-015121

25. Pirkle CM, Dumont A, Zunzunegui MV. Criterion-based clinical audit to assess quality of obstetrical care in low- and middle-income countries: a systematic review. Int J Qual Health Care. 2011;23(4):456-463. doi:10.1093/intqhe/mzr033

26. Bottcher B, Abu-El-Noor N, Abuowda Y, et al. Attitudes of doctors and nurses to patient safety and errors in medical practice in the Gaza-Strip: a Cross-Sectional Study. BMJ Open. 2019;9(8):e026788. doi:10.1136/bmjopen-2018-026788
Clinical Audit

\section{Publish your work in this journal}

Clinical Audit is an international, peer-reviewed, open access journal focusing on the processes and outcomes of clinical audit in any area of healthcare. All aspects of patient care are addressed within the journal and practitioners from all disciplines are invited to submit their work. Areas covered include: Publication of audits; How an audit has changed practice; Practical tips on how to do audits and to

Submit your manuscript here: https://www.dovepress.com/clinical-audit-journal avoid pitfalls; How audits have changed patient care; Calls and justifications for new audits. The manuscript management system is completely online and includes a very quick and fair peer-review system, which is all easy to use. Visit http://www.dovepress.com/ testimonials.php to read real quotes from published authors. 